\title{
The Proceedings of the International Conference
}

on Creationism

Volume 8

Print Reference: Pages 248-254

Article 34

2018

\section{A Model for Outdoor Creation Education}

Jonathan L. Albert

Canyon Ministries

Follow this and additional works at: https://digitalcommons.cedarville.edu/icc_proceedings

Part of the Educational Methods Commons

DigitalCommons@Cedarville provides a publication platform for fully open access journals, which means that all articles are available on the Internet to all users immediately upon publication. However, the opinions and sentiments expressed by the authors of articles published in our journals do not necessarily indicate the endorsement or reflect the views of DigitalCommons@Cedarville, the Centennial Library, or Cedarville University and its employees. The authors are solely responsible for the content of their work. Please address questions to dc@cedarville.edu.

Browse the contents of this volume of The Proceedings of the International Conference on Creationism.

\section{Recommended Citation}

Albert, J.L. 2018. A model for outdoor creation education. In Proceedings of the Eighth International Conference on Creationism, ed. J.H. Whitmore, pp. 248-254. Pittsburgh, Pennsylvania: Creation Science Fellowship. 


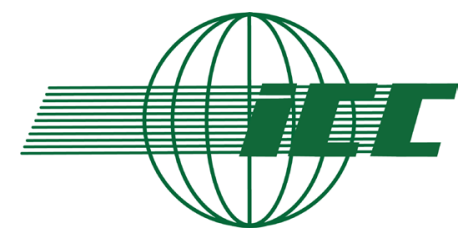

\title{
A MODEL FOR OUTDOOR CREATION EDUCATION
}

\author{
Jonathan Albert, Executive Director, Canyon Ministries, 12921 E. Pine Rock Ln., Suite 50571, Parks, AZ 86018 USA, \\ jon@canyonministries.org
}

\begin{abstract}
Outdoor creation education is critical for encouraging and equipping the saints. A well-organized wilderness classroom opens the eyes of the learner in a unique and inspiring way. The learner gains the heart to love God and others more deeply. The learner also develops the skills necessary to impact others with humble confidence. There are many opportunities right outside our doors to help others engage the wonder of God's creation. With the proper structure, outdoor creation education empowers the teacher and the learner in profound ways, oftentimes unachievable within the traditional classroom.
\end{abstract}

\section{KEY WORDS}

creation, education, relational, outdoor, stewardship, connection

\section{INTRODUCTION}

The purpose of this paper is to provide a model for outdoor creation education. I will present a brief history of Canyon Ministries including how it began and how God has grown our efforts and Kingdom impact. I will also share how we structure our work including objectives, organizational model, core values, and program initiatives. Finally, I will provide instruction and encouragement regarding how others can serve through well organized, quality, outdoor education programming vital to the advancement of the Kingdom. In presenting this model, I hope to encourage others to follow our example so many can be influenced for Christ.

Outdoor creation education utilizes the wilderness setting to minimize life distractions and immerse the student into the glory of God. Isaiah recognized the glory of God revealed in nature as he proclaimed, "Holy, holy, holy is the Lord of hosts; the whole earth is full of His glory!" (Isaiah 6:3 NKJV). Pictures may say a thousand words, but being there in person opens your heart to the transformative power of God. When established as a discipline within the local church, it sets our feet on solid ground and prepares us to be ready to give a reason for the hope we have. A compromised view of Genesis sets the earthly sojourner upon a path away from the core truths of Scripture. Genesis establishes the context for our need of a Savior, the definition of family, and the hope of our future. Many godly organizations have set their efforts upon rightly understanding the Genesis text. The determination of their dedicated, professional research has produced strong teaching tools for the believer and seeker alike.

Numerous styles and contexts have been employed to present this needed information to small groups and to the masses. The most prolific sources available come in written form as books and articles as well as internet videos and DVDs. However, many have looked to more personal and impressionable environments to connect the individual to the information. God has given us meaningful direction to assist us in discovering the environment that deeply connects with and influences the heart of man. God instructs us through His servant, Paul, in Romans 1:19-20 when he says, "because what may be known of God is manifest in them, for God has shown it to them. For since the creation of the world His invisible attributes are clearly seen, being understood by the things that are made, even His eternal power and Godhead, so that they are without excuse" (NKJV). There is no better place to study the work of God than in the midst of the majesty of His work. Luke 5:16 says, "So He Himself often withdrew into the wilderness and prayed" (NKJV). Jesus found strength and sweet communion with God while situated in wild places.

\section{THE STRUCTURE OF OUTDOOR CREATION EDUCATION}

What is Outdoor Creation Education?

Outdoor creation education is the pursuit of a deepened relationship with God and others through the engagement, study, and understanding of the world around us. In this pursuit the wilderness becomes our classroom. This experiential method of learning takes place in the outdoors. It often involves practices in which students participate in a variety of adventure-based challenges. Students develop personal growth while participating in multi-day activities such as backpack journeys, mountaineering, water sports (kayak, canoe, sailing, etc.), and nearly unlimited other outdoor explorations. However, much has also been gained through simple adventures that last only a day or less such as hikes, team-building challenge courses, horse rides, and countless others.

Outdoor education is said to be "in" the outdoors, "about" the outdoors, and "for" the outdoors.

Outdoor creation education can happen in any outdoor setting. This can range from a backyard to a remote wilderness location. It can also vary in length. Great impact can happen in a short afternoon foray to a month-long venture around the world and everything in between.

The topic of outdoor creation education is to seek the person of God through scientific investigation of the physical world around us (Romans 1:20). As such, it is about the outdoors and how it delivers us into the presence of God. 
Outdoor creation education is for the fulfillment of our command to be stewards of what God created. We have a divine command to take care of what was created. Therefore, a purposeful aim of outdoor creation education is for the care and preservation of wild places.

\section{Philosophy/Aims of Outdoor Creation Education}

The aim of outdoor creation education is not the activity itself, but rather to learn how to understand who God is and who we are in relationship to Him and others through a deepened understanding of our physical world. As stated above, outdoor creation education is the pursuit of a deepened relationship with God, and others, through the engagement, study, and understanding of the world around us. These aims are relationally driven as God has created us in His image as relational beings. Some specific outdoor creation education aims include:

\section{To deepen our understanding of and connection with God}

God has chosen to reveal Himself to us through nature. With the Bible as our foundation, we see within creation His desire to redeem man, His relational qualities, and His commands and promises illustrated. Outdoor creation education provides the training needed to develop the skill of seeing and understanding these illustrated principles. The development of this skill involves a combination of formal and informal activities. Initially, the learner is dependent upon the teacher to provide formal instruction and modeling. Over time, that dependency diminishes as the learner gains competency and confidence. There is a necessary informal component as well. The development of this skill is a natural outcome of navigating outdoor adventures and challenges. This requires the teacher to value the learner's ability to figure some things out independently and provide ample time for informal engagement. We see the scars of a global catastrophe upon our earth that reminds us of the destruction of God's judgment. Yet there is immense beauty displayed as well. The presence of beauty woven into God's wrath is a revelation of His heart to redeem man. The purpose of His judgment is redemption rather than destruction. On our river trips through Grand Canyon, we are able to touch rocks understood to be from creation week, as well as rocks laid down during the Flood.

\section{To enhance our connection with the people around us}

Shared adventure in nature creates a bond with those with whom we have interacted. When made a priority, deep relationships form as challenges are overcome and adventures shared. Outdoor education takes us away from our daily distractions and puts the people in front of us into focus. My wife and I have friends all over this planet because we pursue Christ together through a wilderness adventure. I once guided a trip for a struggling family. Over the course of five days, I saw their hearts soften toward one another and find joy in one another once gain.

\section{To understand scientific systems}

Biological and geological systems are on full display in outdoor settings. Nature is a great classroom for investigating what is going on in our physical world. The learner is immersed in the world of interacting ecosystems, geological processes, and abundant biology. The teacher provides the necessary guidance to see beyond the surface of these systems into the intricacies hidden within. For example, visiting an area recently burned provides the learner the opportunity to see the restorative properties of the forest and the critical role fire plays in the cycle of the forest.

\section{To develop habits of stewardship}

Engaging nature provides a healthy understanding of our natural resources and their proper use. Likewise, having great memories of exploring nature builds an appropriate appreciation for nature and desire to keep it clean for the next generation. Environmental responsibility is a significant issue for all to participate in. The learner can be directed to consider local natural resources, and ways to be involved in wilderness care. As urban cultures have developed, our connection to the land around us has diminished. However, we have a deep dependency upon the land. Outdoor creation education is a powerful tool to open the eyes of the learner to that dependency. We tend to care for the things we love and respect. Spending time in the outdoors opens our eyes to the majesty it beholds and our need to care for it for future generations.

\section{To improve leadership and problem solving skills}

Adventures in an outdoor setting often place people well outside their comfort zone. Also, many of the modern day conveniences are not readily available. This forces the learner to find alternative ways of meeting their daily needs. Many outdoor activities require teamwork to accomplish a common goal. These tasks promote healthy communication, positive interaction, and growth of leadership skills. When traveling through Grand Canyon, people are doing life outdoors. We eat, teach, and sleep without any shelter (though tents are available if it gets really bad). This is new to most people. I have observed families working together to find a way to make their little camping area functional. They collectively find ways to minimize the negative effects of the wind, sand, and heat. The individual personalities mesh together to meet a mutual need.

\section{Components of Outdoor Creation Education \\ Biblical education}

We want to better understand God's word through the hands-on illustrations afforded to us in nature. These include illustrated attributes of God and biblical concepts. The Bible comes to life in the world around us. For instance, within Grand Canyon we see illustrated in the metamorphic rocks how heat and pressure work to transform and harden the stone just as the struggles of life work to transform us and harden our faith. Likewise, we are able to touch rocks that we believe date back to the week of creation and also rocks deposited during the flood. In doing so, we are touching the latter rocks that speak of God's defense of His holiness, His hatred of sin, and His heart to redeem man.

\section{Adventure education}

Adventures reveal much about who we are such as our fears, strengths, skills, and passions. Shared ventures help us understand how to interact with the people around us. The outdoor classroom is a dynamic place to learn both interpersonal and intrapersonal relationships. For generations, parents have counseled their children during hard times that it "builds character." The truth is that those times of great struggle reveal character strengths and weaknesses more than build them. The stressors associated with outdoor endeavors effectively reveal our character while simultaneously providing the means to develop it. 
Interpersonal relationships refer to one's understanding of group dynamics and the development of biblical servanthood. This is illustrated by the development of team and the bonding established by shared challenges. During the river trips, the rafts need to be loaded and unloaded each day. The massive amount of equipment requires the group to work together to get this done. The leaders and workers find their place within this process and work together to accomplish the task. Intrapersonal relationships refer to how we understand ourselves as created beings set in a relational context with purpose and design. This takes place in the heart and mind as our paradigm is altered by new information and overcoming challenges. Our river trips through Grand Canyon challenge people to face fears and limits. We see many grow in confidence through the completing of a hike or simply surviving a night sleeping outdoors.

\section{Environmental education}

This is our focus upon the understanding of, and interacting within, the environment. This educational focus sets the learner's mind and heart upon the disciplines of stewardship, interdependent ecosystems, mankind's dependency and interaction with the land, and outdoor living skills (i.e. trust, safety, survival, and recreation). One way to foster this is to do more than just "use" the wilderness. Many trail associations need volunteers to help maintain trails so participating in that kind of activity unites the action with the heart of service.

\section{Models}

There are a variety of models for setting up outdoor adventures. Each of these contains their own individual strengths and weaknesses. Launching an outdoor creation education program in the local church will most likely interact with each of these models.

The Club Model is an established organization with an outdoor focus. This typically includes officers, member requirements, and possibly dues. An example may be a church hiking club.

The Instructional School Model has a designated instructor who teaches a class that fits into a larger scope and sequence. Students enroll in a program with fees or tuition. A class in survival skills fits this model.

The Guided Package Model has a designated guide that directs the undertakings of the adventure. The participants show up with limited personal gear and the guide provides everything else. (Canyon Ministries falls under this model.)

The Common Adventure Model has no designated leader and all participants share the trip costs. This model might be a group of friends deciding to take a multi-day backpacking trip on the Arizona Trail.

\section{Topics covered}

There are nearly limitless topics that can be addressed in the outdoor setting. Some of the likely topics to be investigated are leadership, survival skills, team building, relationships, environmental responsibility, and sciences such as geology and biology. An effective outdoor creation education program seeks to find a balance between typical outdoor disciplines and spiritual disciplines. The well-prepared teacher can creatively weave developing leadership skills, environmental responsibility, and survival skills into a single activity. Reflection upon the activities often reveals the spiritual truths on display such as redemption, the nature of God, and prayer.

\section{Teacher responsibilities}

Teachers shoulder a significant responsibility when stepping in front of students. The outdoor environment holds some that differ from the traditional classroom. Responsibilities unique to the outdoor education model include safety concerns associated with outdoor adventures and travel as well as activity logistics.

Psalm 78:72 provides great insight for the role of the teacher. It says that David shepherded his people with integrity and skill. The teacher is responsible to be prepared. There are unforeseen things that can arise in the outdoor classroom, but great preparation minimizes those and helps the teacher respond appropriately when they occur. This preparation will manifest itself in the depth of understanding of material, technical skill, safety, enthusiasm, and an obvious commitment to learning.

The teachers are also responsible to conduct themselves with integrity. This will be evident in environmental ethics, servant leadership, and refraining from partiality.

\section{Benefits of outdoor creation education}

The outdoor classroom is a powerful environment for achieving maximum benefits. Disconnecting from everyday distractions allows the teacher and learner to place their focus upon what is directly in front of them. The result is a context appropriate for life-on-life instruction/discipleship. The hands-on process of outdoor education promotes motor skills and often reveals new interests, competencies, and a passion for learning. The physical rigors of outdoor education promotes healthy lifestyles resulting in physical strength and peace of mind. The relational aspect of the outdoor classroom develops leadership skills, people skills, and our understanding of being created in the image of a relational God.

\section{Limitations of outdoor creation education}

The unique challenges of outdoor education should be seen as opportunities rather than barriers. However, the outdoor classroom does present some obstacles to be prepared for. There are often extra costs (some of them significant) associated with outdoor education due to equipment needs, travel, and partnership with other organizations. Additionally, there are greater risks involved in outdoor activities that place an extra burden upon the teacher for safety. The outdoor environment itself can be a challenge as well. This can be related to weather, terrain, animals, or insects.

\section{Assessment}

It is important to evaluate the effectiveness of the program and make necessary adjustments along the way. Assessment can be challenging at times; below are a few traditional ways of measuring results.

Providing a survey at the conclusion of the activity invites open communication from the participants. This helps provide the teacher with what has or has not been effective. The survey should be short, simple, and direct.

One simple way of assessment is paying attention to the people. First, do people want to participate? We all love to be a part of something fun and significant. If nobody is showing up, then 
something needs to be changed. Second, pay attention to the students and look for recognizable change. You may notice a difference in confidence, demeanor, servant heart, direction, leadership, knowledge of God's Word, and others.

\section{CANYON MINISTRIES: AN EXAMPLE OF OUTDOOR CREATION EDUCATION}

\section{History of Canyon Ministries}

Canyon Ministries has existed since 1997 with a sincere dedication to proclaim the truth of God's Word through education and adventure in the wilderness setting of the Grand Canyon. Here is how we got to where we are today.

In 1980, Tom Vail took what would be a life-changing vacation - a rafting trip through the Grand Canyon. Two years later, he left his corporate job to become a rafting guide.

For the next 15 years, Tom led trips through the Grand Canyon and taught that natural (evolutionary) processes over millions of years were responsible for forming the varied rock layers found in the Grand Canyon.

In July 1994, a lady went on a Grand Canyon rafting trip and Tom was one of her guides. On the second night of the trip, she started her ministry on his lost soul, planting seeds that would flourish into a "new birth." After the trip, she sent Tom a Bible that traveled with him to the Himalayas in Pakistan. It was there, through reading God's Word, that Tom accepted Christ as his Lord and Savior. The following year that lady became Mrs. Paula Vail.

A year later, while living in North Carolina, another seed was planted which germinated into Canyon Ministries, with its first trip through the canyon in 1997. Jon Albert was brought on as Canyon Ministries' Executive Director in 2013. Under Jon's direction, the ministry has expanded from solely river trips to include biblically based rim tours of the canyon.

\section{The Mission of Canyon Ministries}

Canyon Ministries is dedicated to upholding the authority of Scripture from the very first verse and presenting the evidence seen in and around the Grand Canyon, which supports a young earth.

We have two core methods of fulfilling the mission we have been given.

1. Canyon Ministries facilitates trips of whitewater rafting and hiking in Grand Canyon and surrounding area. These adventures are dedicated to directing the guests to God's Word by teaching a literal interpretation of Genesis and presenting the geology of Grand Canyon through a biblical lens.

2. Canyon Ministries provides guided bus tours on the South Rim of Grand Canyon. These tours are committed to directing the guests to God's Word and understanding the formation of Grand Canyon through a literal interpretation of the Genesis Flood account.

We hold to three core tenets that provide direction to our efforts.

1. We must remain true to God's Word and honor it as authoritative. We believe it is His specific revelation of Himself to us. This includes a right understanding of the book of Genesis as a historical narrative of our beginnings and its direct connection to the gospel.
2. We need to be diligent in our understanding and interpretation of God's general revelation, the world around us. This drives us to be certain that we present well-researched and peerreviewed science.

3. The methods and attitudes through which we engage people profoundly affect the impact of the ministry. 2 Timothy 2:24 says, "And a servant of the Lord must not quarrel but be gentle to all, able to teach, patient" (NKJV).

\section{The Heart of Canyon Ministries}

Canyon Ministries is built around relationships. We are instructed in Matthew 6:33 to seek first the Kingdom of God and His righteousness. The Kingdom is first and foremost a "Who", not a where. It is the person of Jesus. Righteousness is only found in Christ. Therefore, we are instructed twice in a few short words to seek first the person of Christ. This means that all Kingdom work is a relational pursuit of Jesus as our Savior. We are dedicated to obeying that command in how we function within Canyon Ministries.

This truth is revealed in creation. The relational, triune nature of God is the blueprint for the relational context of creation. Nothing exits alone. God did not just create "things," but rather systems. Each day of creation represents a diverse and complex system of organisms (each according to its kind). At the end of each day, He called it "good." This repeated itself day after day until the creation of Adam. Genesis 2:18 says, "The LORD God said, 'It is not good for the man to be alone. I will make a suitable helper for him"” (NKJV). Upon creating Adam, God had created something existing alone. This was "not good" in the eyes of a relational God. God remedied this through the creation of Eve, thereby establishing the intimate relationship of marriage.

For a time, all of creation enjoyed a perfect relationship. It is likely that Adam and Eve walked and talked with God in the garden. But the tempter came and pulled Adam and Eve away. God had a plan already in place to reconcile all of creation to Himself. Creation reflects this message.

This determines the context for the significance and necessity of creation education within the church and why Canyon Ministries exists. God has made it abundantly clear that knowledge of Him is obtained through creation. Romans 1:20 says that His invisible qualities have been made plain through creation. We are called to pursue the person of God through the understanding of what $\mathrm{He}$ has made. This is creation education.

\section{The Structure of Canyon Ministries}

The organizational model of Canyon Ministries stresses the significance of relationships and a team effort. The work we do is not the result of any one individual, but rather the collective effort of a team. We are established as a $501 \mathrm{c}(3)$ non-profit organization.

Our team includes four pieces.

1. The board of directors meets two times each year. We have seven people on our board and each individual brings a set of skills that complement one another.

2. Our staff is comprised of the Executive Director, Director of Rim Tour Operations, and Office Administrator. We lean 
on one another to ensure we serve with excellence. We also depend on one another to respect each other's schedules for down time and family time.

3. The guides are directly serving the guests on the river and on the rim. Our guides serve with the heart of a shepherd. Psalm 78:72 presents the principle of serving our guides follow. "With upright heart he shepherded them and guided them with his skillful hand" (NKJV). Both our Executive Director and the Director of Rim Tour Operations serve as guides along with their other duties.

4. We are blessed to partner with organizations and individuals. The organizations we partner with (e.g., Answers in Genesis and Institute for Creation Research) share a common purpose and are a great source of encouragement. They provide some of their scientists to be specialist-teaching guides on some river trips. The individuals provide powerful prayer support and help meet our financial responsibilities through generous donations.

The Kingdom is most powerfully advanced and God most deeply honored when these four pieces work in humble unity. We accomplish together what no individual could accomplish alone.

\section{The Service of Canyon Ministries}

Our emphasis upon relationships is also deeply evident in the manner of our service. We educate our guides to view themselves as shepherds. Again, we lean upon the example given by David in Psalm 78:72. God grants us the divine privilege of serving our guests for as little as four hours to as many as nine days. The time that we have with them is precious. Our goal is to direct their heart toward God. This requires our guides to connect with the guests and serve them according to their needs and passions. We do not try to squeeze all the people God brings into the same box. We want to get to know them as best we can in the time we have and customize the experience to them. This also requires our guides to bridge the information to the heart of God. We are deliberate in asking and answering, "What does this tell us about who God is?" The next important question is, "What does this mean for us today and for our future?" As incredible as Grand Canyon is, the thing that encourages people the most is the relationships they develop with others on the tour and with us.

The 2017 river season certainly reflected this truth. In our $20^{\text {th }}$ year, God gathered people from all over the world to adventure together in Grand Canyon and celebrate His eternal goodness. Rafting through the heart of Grand Canyon emphasizes the majesty of God in a multiplicity of ways. Wilderness travel exposes our dependency. The energy required for simple tasks reflects our need to contend for the faith. The fossils buried within the rock layers speak of God's judgment. The beauty that surrounds us announces the redemptive nature of God and His divine majesty. However, perhaps the most significant experience is the unity of believers sojourning together. Every trip reflects the prayer of Jesus the night $\mathrm{He}$ was betrayed when He asked that we would be one just as $\mathrm{He}$ and the Father are one. Within the hallowed walls of Grand Canyon, differences dissolve and connections are created. The distractions of everyday life are nearly obsolete. The people and needs directly in front of us are all that occupy our attention. The thrill of developing relationships filled with laughter, tears, prayer, spoken Scripture, worship, and encouragement dwarfs the thrill of the whitewater.

We have prayed for broken marriages, loved on prodigal children, shared and enhanced dreams, developed ministry plans, mentored across generations, and more. There are no socioeconomic distinctions, no racial preferences, nor is there gender discrimination. We experience the church, the Bride of Christ united in purpose and effort. It's no wonder this is what transforms people the most and makes the deepest impression.

\section{The Growth of Canyon Ministries}

God has shown His favor to us. We have enjoyed steady growth from year to year. From 2014 to 2015, we were able to grow by $60 \%$ in the number of people we served. From 2015 to 2016, we again grew by an additional $60 \%$. In 2017, we had the privilege of serving over $100 \%$ more people than we did in 2016, roughly 1,500 people on our rim tours alone. As we look closely at the key indicators, we believe we are poised to experience another $100 \%$ growth rate for 2018 .

These numbers are not shared as a point of egotism. Our growth is the direct result of God's work at Grand Canyon and a reflection of the relationship focus we hold to. We have improved our marketing strategy and expanded our presence and we trust those efforts are being rewarded. However, we firmly believe our growth is more significantly the result of an intentional effort to establish and cultivate the relationships described above. We have seen this reflected in the prayer, marketing, and financial support we have received. We also hear it from our guests. We often receive comments about the personal care we give to our guests. People go away from a Canyon Ministries experience feeling loved and celebrated. This makes them want their friends and family to experience Grand Canyon with us as well. Information alone can be acquired through books and videos. But, connecting with God and others through that information requires being there.

\section{HOW TO BEGIN}

Starting any new venture can be intimidating. The following section seeks to provide a step-by-step process that can be followed to ensure that whatever the level of outdoor creation education is engaged is purposeful, well-organized, safe, fun, and effective.

\section{Pray}

Outdoor creation education is primarily a spiritual endeavor and must be treated as such. There are significant systemic pieces to put in place, but the Spirit of God and His pleasure in our work hold them together. Prayer is the catalyst for all Kingdom work. The pursuit of things by earthly means limits the outcomes to earthly results. The pursuit of things by eternal means produces eternal results.

\section{Begin Where You Are}

It is important to begin the process by discerning what opportunities are readily available in your area. God's majesty is in our midst everywhere. It is not necessary to travel halfway around the world to see God. These "big adventure" trips are fantastic and may be something you do in time, but begin with the resources out your front door. Simple experiences that don't require a massive organizational effort and lots of money can have just as much 
effect. Don't underestimate the thoughtful walk through a city park, a half-day paddle on a small river, the visit to a zoo, a sunset picnic at a scenic overlook, or a host of other simple activities.

It is also important to begin where you are in regards to knowledge. Nobody has all the answers. Identify what the educational focus can be based upon local resources. This may include potential teachers, outdoor facilitators, written resources, or outdoor organizations.

The Kingdom needs God's majesty proclaimed right where you are. Get people involved in your area. You can organize a monthly hike, kayak/canoe float, bike ride, etc. The national parks are great classrooms. You can utilize the opportunities these parks generate.

\section{Form a Team}

The "lone wolf" mentality and ministry is inherently limited in scope and effectiveness. The following is a list of potential roles to be filled by various team members. One person can fulfill more than one role, but the more specifically each team member is cast, the more efficient and effective they (and the team) will be.

The leader is the person responsible to set the vision (activity, focus, objectives/aims) and keep team members on task. During the activity, the leader is the host. The leader is responsible to set up the teacher or facilitator (if that person is someone other than themselves).

The organizer coordinates the logistics associated with each activity/adventure. This may include transportation, food, equipment, outside organizations, acquiring necessary permits or licenses, and recording what took place to be used for evaluation and future planning.

The teacher is the chief communicator of the information as determined by the objectives of the event.

The facilitator leads the activities of the event. It may be teambuilding games, outdoor activities (biking, canoeing, hiking, etc.), challenge skills, or others.

The fundraiser is responsible for acquiring the funds necessary for the activity.

The communicator organizes the timing, tone, and mode of communication to the appropriate people (guests, students, parents). This person may also choose to write an article for a local paper or blog site as a follow up.

\section{Keep It Focused}

There are many exciting things to do in the wilderness and many objectives to aim for. This is a great blessing of outdoor education, but it can also be overwhelming and distracting. Time must be taken to determine the ultimate objective of each outing/class/ activity/trip. There are four key areas to consider in this process.

1. Target group: Who is the key affinity group to be reached?

2. Educational/spiritual objective(s): What is the desired outcome?

3. Activity: What activity best accomplishes the objective(s)?

4. Assessment: How will you know it has been successful?

\section{Establish Resources}

The greatest car in the world can be built, but if it doesn't have any fuel it doesn't go anywhere. Being intentional in the area of resources is fundamental to a successful ministry. There are four pools of resources to supply.

\section{Human resources}

This is more than just having warm bodies. The people enlisted should fulfill three categories: 1) a knowledge/skill base, 2) the desire to serve, 3 ) the capacity to serve.

\section{Written resources}

There are a host of individuals doing great scientific work. Their research and findings generate a great amount of information needing to be shared. Generate a library of written and online resources for people to do their own study beyond what is presented during the activity/event. It is very important that the teacher establish a resource library for their own development and equipping. Find the resources to have a solid understanding of the rocks, flora, fauna, and history of the area.

\section{Financial resources}

Programs take money. This can be accomplished through fundraising, fees, sponsorship, or a combination thereof.

\section{Physical resources}

The physical needs will vary from activity to activity. This includes the vehicles, technology and adventure gear (camping, climbing, water sports, etc.). This can be a large financial burden. However, there is a host of ways to accommodate these needs. They can be acquired by donations, purchase, or rental. Begin by establishing what is required and then identifying the donation, rental, and purchase options.

\section{Advertise}

People can only participate in activities they know are happening. Be sure this is a thoughtful discipline rather than an afterthought. Communicate early and often about what is happening and the established objectives. Communication about the event should include all the basics of who, what, where, when, why, and how. It is important to include testimonials, pictures, and videos.

\section{Execute}

The manner of execution will make or break it all. A successfully executed outdoor creation education activity/event/adventure requires the following pieces.

\section{Relationally-driven}

Outdoor creation education is the pursuit of a deepened relationship with God and others through the engagement, study, and understanding of the world around us. This drives the context and environment within which the program functions. The program structure must value people over process. The leaders must value people over information. The goal is to engage the heart as well as the brain. Christ gave us a great example in John 13. Jesus was about to meet with his closest companions for the last time prior to His death. He had a lot He needed to share with them about what was about to happen, why it was going to happen, and what they were to do in response. However, before He spoke, He served. Jesus first engaged the heart of the disciples by washing their feet. $\mathrm{He}$ connected with them relationally around the table and then $\mathrm{He}$ 
proceeded to convey information.

\section{Joy and gratitude}

We go out of our way to be around people who are genuinely joyful and thankful. The same is true for educational settings. The characteristics of joy and gratitude create a positive learning environment found to enhance the students' engagement and overall success.

\section{Integrity and skill}

This has already been discussed above, but needs to be reemphasized here. We must do all things with excellence and above reproach. In outdoor education, lack of skill can result in physical harm to those involved, while a lack of integrity can destroy the very foundation of your ministry.

A practical application of this is to be certain that the teacher and the student are adequately matched. It wouldn't be fruitful to have a scientist teaching technical data to a group of younger students. Likewise, an audience of well-educated individuals with field experience would require a more technical approach to keep them engaged.

\section{Evaluate}

There must be an intentional process for evaluating the effectiveness of the program. Evaluating the outcome is crucial. During times of evaluation, God provides direction and growth. It is important to humbly listen to the reactions people have. Growth and improvement only come through intentional review. Ask important questions like what worked, what didn't work, and why it did or did not work. Don't rely on your own perspective, but enlist the help of other people (i.e. helpers and participants).

\section{CONCLUSION}

I have provided a definition for outdoor creation education including its aims and objectives. Outdoor creation education is the pursuit of a deepened relationship with God and others through the engagement, study, and understanding of the world around us. The aim of outdoor creation education is not the activity itself, but rather to understand who God is and who we are in relationship to
Him and others through a deepened understanding of our physical world. Outdoor creation education has a biblical component, an adventure component, and an environmental component interrelating with one another as the teacher and students interrelate with creation and each other.

The history and structure of Canyon Ministries was provided to illustrate how outdoor creation education can have great results. Canyon Ministries is a currently functioning outdoor ministry seeking to uphold the authority of Scripture from the very first verse and presenting the evidence seen in and around the Grand Canyon, which supports a young earth.

I have also provided some steps to follow in developing your own outdoor creation education program, pressing upon the significance of doing everything with excellence and skill.

At the turn of the twentieth century, Theodore Roosevelt pioneered the emergence of the conservation movement during the progressive era in America. The government took on the huge task of claiming large sections of land that would later become our National Monuments and Parks. Although the earthly American government was primarily looking to protect wild places for simple enjoyment, I believe that God was sovereign over that movement to protect and preserve the greatest of all classrooms. It is time for God's people to use these tracts of land for Kingdom purposes by means of creation-based education-in other words, the greatest spiritual good for the greatest number of people.

\section{THE AUTHOR}

Jon Albert is currently the Executive Director of Canyon Ministries. He received a B.S. in Bible and Ministry from Northwestern University in St. Paul, MN. He also received his M.TH. from the same university. Jon has served as an associate pastor and a senior pastor. He has also worked in education administration both in the public and private arena. Jon has been a commercial wilderness guide since 1992. He and his wife founded an outdoor adventure creation ministry called, Gloryview in 1999. Jon has been developing (including curriculum writing) and leading outdoor adventure creation education for 25 years. 